\title{
O CZYM MÓWIMY, KIEDY MÓWIMY O KULTURZE POLICYJNE)?
}

\author{
WHAT WE ARE TALKING ABOUT WHEN WE TALK \\ ABOUT POLICE CULTURE?
}

Katarzyna Amrozy*

\begin{abstract}
ABSTRAKT
Celem niniejszego artykułu jest wyjaśnienie, co rozumiemy pod pojęciem kultury policyjnej. Ogólnie można ją rozumieć jako zbiór formalnych i nieformalnych zachowań oraz wartości, typowych dla tej grupy dyspozycyjnej. Na charakterystyczne cechy składają się takie elementy jak: argot, cynizm, wewnętrzne sankcje, solidarność, izolacja społeczna czy specyficzna percepcja przemocy. Pełnione przez policyjną kulturę organizacyjną funkcje (integracyjna, percepcyjna, adaptacyjna, budująca tożsamość, stymulująca zmiany) kształtowane są na podstawie codziennych działań policji. W tekście wymieniono również działania, za pomocą których kultura policyjna rozwija się i kształtuje.

Słowa kluczowe: kultura policyjna, kultura organizacyjna, kultura bezpieczeństwa, kultura służb mundurowych, grupa dyspozycyjna
\end{abstract}

The purpose of this article is to explain what we mean by a police culture. In general, it can be understood as a set of formal and informal behaviours and values typical of this disposition group. Characteristics include such elements as argot, cynicism, internal sanctions, solidarity, social isolation or specific perception of violence. The functions of the police organization (integration, perception, adaptation, identity-building, stimulating change) are based on daily police activities. The text also mentions the activities by which police culture develops and shapes.

Keywords: police culture, organizational culture, security culture, security service culture, dispositional group

* Uniwersytet Mikołaja Kopernika w Toruniu, Wydział Politologii i Studiów Międzynarodowych. 
Thank God for police culture

(Beal, 2017)

Celem niniejszego artykułu jest zaprezentowanie pojęcia kultury policyjnej, przedstawienie jej charakterystyki oraz sposobów jej tworzenia. Można bowiem zaobserwować, że choć badania w tym zakresie prowadzone są mniej więcej od lat 80. XX wieku (Hołyst, 2011), to nie każdy wie, co kryje się pod tą kategorią. Aby wyjść od tego, czym jest kultura policyjna, należy wyjaśnić dwa inne określenia, które są ze sobą powiązane i pozwalają lepiej zrozumieć to zjawisko. Chodzi tutaj o kulturę bezpieczeństwa oraz kulturę organizacyjną. Należy przy tym pamiętać, że nie ma jednej konkretnej definicji, pozwalającej na całościowe ogarnięcie omawianego terminu.

\section{KULTURA BEZPIECZEŃSTWA}

Wyjaśnienia zagadnienia kultury bezpieczeństwa podjął się Marian Cieślarczyk (2009), który traktuje ją jako: „wzór podstawowych założeń, wartości, norm, reguł, symboli i przekonań, charakterystycznych dla danego podmiotu, wpływający na sposób postrzegania przez niego wyzwań, szans i (lub) zagrożeń w bliższym i dalszym otoczeniu, a także sposób odczuwania bezpieczeństwa i myślenia o nim oraz związany z nim sposób zachowania i działania (współdziałania), w różny sposób przez ten podmiot „wyuczonych” i wyartykułowanych, $\mathrm{w}$ procesach szeroko rozumianej edukacji, w tym również $\mathrm{w}$ naturalnych procesach wewnętrznej integracji i zewnętrznej adaptacji oraz $\mathrm{w}$ innych procesach organizacyjnych, a także w procesie umacniania szeroko rozumianej obronności, służących w miarę harmonijnemu rozwojowi tego podmiotu i osiągania przez niego najszerzej rozumianego bezpieczeństwa, z pożytkiem dla siebie, ale i dla otoczenia".

Wynika z tego, że kultura bezpieczeństwa, w reakcji na doświadczane wydarzenia oraz na proces edukacyjny, nieustannie się zmienia. Składa się ona z następujących elementów: kultury mentalnej i duchowej (wartości, zasady, normy, wiedza, „technologie intelektu”), kultury organizacyjnej (regulacje prawne, struktury organizacyjne, procedury) oraz kultury materialnej (infrastruktura, sprzęt techniczny, stanowiska pracy). Te części łączą się ze sobą i wzajemnie przenikają. Funkcje pełnione przez kulturę bezpieczeństwa można analizować poprzez odniesienie do różnych grup społecznych, społeczności lokalnych, 
narodów, ale także, zdaniem Mariana Cieślarczyka (2009), w stosunku do „różnych wymiarów bezpieczeństwa i obronności, dla struktur organizacyjnych, ale i struktur świadomości”. Te funkcje to: integracyjna, adaptacyjna, stymulacyjna oraz regulacyjna. W kontekście omawianego w tym artykule tematu należy wspomnieć, że ze względów praktycznych i teoretycznych nauki policyjne zostały włączone do kategorii nauk o bezpieczeństwie.

\section{KULTURA ORGANIZACYJNA}

Kultura organizacyjna (inaczej: kultura zawodowa, kultura instytucji, kultura korporacji) to pojęcie szerzej omawiane na gruncie nauk o zarządzaniu. W tym ujęciu odnosi się bezpośrednio do firm czy też instytucji, jednak można to przełożyć także na rozważania o policji lub innych służbach związanych z bezpieczeństwem, czyniąc z tego zagadnienie interdyscyplinarne. Przywoływany powyżej Marian Cieślarczyk (2003) zauważa, że zainteresowania badawcze nad kulturą organizacyjną odnoszą się do niej jako zjawiska społecznego oraz znaczenia owej kultury dla funkcjonowania systemu. Za Joanną Paliszkiewicz (2010) przytoczę definicję Daniela Denisona, interpretującego kulturę organizacyjną w sposób następujący: „odnosi się do głęboko ukrytej struktury organizacyjnej, opartej na wartościach, przekonaniach i założeniach reprezentowanych przez pracowników. Znaczenie ustala się poprzez socjalizację w ramach grup o różnej tożsamości, które współistnieją w miejscu pracy. Poprzez interakcje buduje się świat symboli, który z jednej strony, zapewnia kulturze dużą stabilność, a z drugiej nadaje jej pewną kruchość i chwiejność wynikającą z zależności systemu od jednostkowych zachowań i procesów poznawczych". Innymi słowy można powiedzieć, że kultura organizacyjna jest zbiorem formalnych i nieformalnych reguł, zachowań, norm, które określają funkcjonowanie danej organizacji oraz warunkują ich stosunki z osobami spoza grupy.

Według Katarzyny Koniecznej (2015) katalog zasad postępowania, widoczny w wewnętrznych relacjach, składa się z następujących czynników: systemów motywacyjnych, sposobów wynagradzania, ścieżek kariery, deklarowanych i przestrzeganych hierarchii wartości, wartościowania pracy, poziomu satysfakcji oraz lojalności pracowników, sposobu sprawowania władzy, relacji pomiędzy kierownictwem a pracownikami, wzajemnego komunikowania się, otwartości na innowacje i zmiany organizacyjne. 


\section{KULTURA POLICYJNA}

Powyższe definicje mogą nakreślać, czym jest kultura policyjna i jak należy ją rozumieć. Wynika to z tego, że policja, jako służba odpowiedzialna za zapewnienie bezpieczeństwa, tworzy swoją własną kulturę organizacyjną, składającą się ze specyficznych dla niej elementów. Podobnie moglibyśmy odnieść się do innych grup wchodzących w skład służb mundurowych, bowiem: „każda organizacja ma pewien styl, charakter, specyfikę funkcjonowania, które w bardzo dużym stopniu wpływają na to, co dzieje się wewnątrz niej i na jej kontakty z otoczeniem” (Hołyst, 2011). Megan O’Neill oraz Anne-Marie Singh (2007) ujęły kulturę policyjną jako pełnienie przez funkcjonariuszy służby nie zawsze w sposób książkowy, ale nie wykluczający go. Ponadto, według autorek, policja ma społecznie skonstruowany sposób postrzegania świata.

Kultura policyjna nie jest monolitem - nieustannie zmienia się i dzieli na poszczególne etapy przyswajania przez policjanta jego roli. Style funkcjonowania policjantów oraz ich wyobrażenia kształtują się na bazie codziennych interakcji. Także sama policja, co można zaobserwować podczas śledzenia jej historii, zmienia się i dostosowuje (a przynajmniej próbuje) do wymogów współczesnego świata. Postrzeganie policji przez obywateli również ulega przeobrażeniom, choć w świadomości niektórych osób dalej funkcjonuje myślenie na zasadzie „milicja, narzędzie opresji władzy”.

\section{CHARAKTERYSTYKA KULTURY POLICYJNEJ}

Warto postawić sobie pytanie, co charakteryzuje kulturę policyjną? Według Brunona Hołysta (2013), przywołującego badania Andrea Hollingshead’a i Georga Kirkhama, są to następujące komponenty:

- $\operatorname{argot}$ (żargon) - specjalistyczne słownictwo funkcjonariuszy, wywodzące się z codziennej komunikacji między policjantami, jego części składowe nie zawsze są zrozumiałe dla osób postronnych ${ }^{1}$;

${ }^{1}$ Należy także zauważyć, że policyjny argot będzie się różnił między sobą nie tylko na gruncie państwowym, ale także w skali różnych miast, bowiem w dużej mierze żargon czerpie swoje wyrażenia z gwary, slangowych określeń oraz określeń typowych dla danego regionu. 
- „wiedza ezoteryczna” - czyli przyswajanie właściwych dla tej służby norm postępowania, kształtujące się już od etapu szkoły policyjnej, mającej na celu zgodę dla formalnych i nieformalnych kodeksów policyjnych;

- cynizm - rozumiany jako realizm, „przechodzenie początkującego policjanta od modelowej wyidealizowanej roli w szkole policyjnej do praktyki dnia codziennego w czasie patrolowania ulic" (Hołyst, 2013);

- wewnętrzne sankcje - mające na celu kontrolowanie wzajemnych relacji między policjantami a nie-policjantami oraz ich wzajemne stosunki, to także poczucie lojalności wobec wykonywanej profesji;

- solidarność - wyrażona jako podtrzymywanie na duchu i umacnianie wiary w siebie każdego funkcjonariusza, pozwalające na znoszenie przeciwności z zewnątrz;

- izolacja społeczna - specyfika tej służby sprawia, że funkcjonariusze stykają się z niechęcią części obywateli, niekiedy problem ten dotyczy także rodziny policjantów;

- percepcja przemocy i dystansu psychologicznego - umożliwia zachowanie obiektywnego stosunku oraz dystansu w trakcie służby.

Dodatkowo Brunon Hołyst (2011) wyszczególnia także ceremonie, nagrody, określony wystrój oraz inne formy komunikowania się, jako przejawy owej kultury.

Podobnie charakterystyczne cechy postrzega Tom Cockcroft (2013). Kluczowe, jego zdaniem, punkty tradycyjnego podejścia w myśleniu o kulturze policyjnej, to:

- poczucie misji/sposób życia (sense of mission/way of life) - to idea, według której policjanci reprezentują wybitnie moralną postawę, prezentowanie wyidealizowanej wizji ich służby oraz podobnych doświadczeń w sferze „wiedzy tajemnej”;

- cynizm/pesymizm (cynicism/pessimism) - rzeczywistość, której policjanci doświadczają na co dzień, kształtuje ich patrzenie na świat, co może prowadzić do odczuwania negatywnych emocji wobec całego społeczeństwa lub pewnych jego grup, przykładowo bezdomnych lub prostytutek, ale również względem systemu prawnego, powiązań między polityką a policją, stylów zarządzania;

- podejrzliwość (suspicions) - służba w stanie ciągłego napięcia sprawia, że policjanci muszą szybko klasyfikować odbierane bodźce, dodatkowo policjanci są szkoleni do radzenia sobie z nieprzewidywalnymi i potencjalnymi zagrożeniami; 
- izolacja/solidarność (isolation/solidarity) - wzajemne wspieranie się przez policjantów, łączą ich „wspólne interesy” oraz pewnego rodzaju braterstwo, to przywiązywanie większej wagi do relacji nawiązywanych w trakcie służby;

- dyskrecja (discretion) - decyzja o podjęciu lub niepodjęciu reakcji na dane wydarzenie lub o sposobie interwencji².

Ciekawy komentarz do powyższych charakterystyk przedstawia Kornelia Oblińska (2015), stwierdzając: „Kultura organizacyjna Policji musi uwzględniać swoisty dualizm funkcjonowania poszczególnych jej uczestników, gdyż bardzo często podczas jednej interwencji funkcjonariusze Policji muszą wykazać się stanowczością i zdecydowaniem, często brutalnym działaniem w konfrontacji z przestępcami i sprawcami przestępstw, zaś z drugiej strony łagodnością, empatią, współczuciem i troską w stosunku do ofiar przestępstw. Bez wątpienia wpływa to na stan psychofizyczny funkcjonariuszy, którzy są narażani na permanentny stres, ryzyko utraty zdrowia oraz życia. Tym samym wymagają szczególnego poczucia tożsamości zawodowej oraz odpowiedzialności społecznej za wspólne bezpieczeństwo".

\section{FUNKCJE KULTURY POLICYJNEJ ORAZ SPOSOBY JEJ BUDOWANIA}

Kultura policyjna, podobnie jak kultura organizacyjna danego przedsiębiorstwa, pełni określone funkcje, specyficzne dla służby bezpieczeństwa:

- integracyjna - podobne rozumienie określonych pojęć oraz wspólny język;

- percepcyjna - podobne postrzeganie otoczenia, wspólne cele, zadania do realizacji;

- adaptacyjna - dostosowywanie się do przyjętych reguł, akceptacja zasad;

- budowania tożsamości organizacji;

- stymulowanie zmian organizacyjnych (Oblińska, 2015).

Tak jak w przypadku elementów tworzących kulturę bezpieczeństwa, tak i te funkcje łączą się ze sobą i odnoszą do podobnych działań.

2 Andrzej Pawłowski definiuje dyskrecję zawodową policjanta, zauważając: „oprócz tajemnicy państwowej i służbowej, których przestrzeganie jest unormowane prawnie, stanowi moralny obowiązek zachowania milczenia o wszelkich sprawach prywatnych dotyczących osób i zdarzeń, niemających bezpośrednio znaczenia policyjnego". Pawłowski, A. (2001). W: W. Pływaczewski, G. Kędzierska (red.), Leksykon policyjny. Szczytno: Wydawnictwo Wyższej Szkoły Policji. 
Działań, za pomocą których można kształtować kulturę policyjną, jest wiele. Dotyczą zarówno samych policjantów, ich rodzin, lecz są także kierowane do całego społeczeństwa. Część badań, poświęconych stosunkowi obywateli do tej formacji, wskazuje, że mundurowi cieszą się zaufaniem większości respondentów (Większość Polaków deklaruje swoje zaufanie do policji, 2017). Wysoką ocenę policja uzyskuje również za prowadzoną działalność (Policja najlepiej oceniana służbą mundurową, 2017), przegrywając jedynie z dwoma stacjami telewizyjnymi oraz władzami samorządowymi. Te wyniki pokazują głęboką przemianę polskiej policji, nie tylko w porównaniu do czasów peerelowskiej milicji, ale także z początków swojego funkcjonowania w latach 90. ubiegłego wieku. Wiąże się to zarówno z lepszym wyposażeniem i wykształceniem funkcjonariuszy, jak i ze zmianą mentalności części obywateli.

Jako przykładową akcję, spełniającą zarówno funkcję integracyjną oraz budującą, można wymienić Międzynarodowy Turniej Służb Mundurowych w Piłce Halowej im. podkom. Andrzeja Struja. W 2017 roku nadinsp. Jan Lach, rozpoczynając sportowe zmagania, przypomniał, że „główny cel turnieju to upamiętnienie bohaterstwa funkcjonariusza Policji, który rotę ślubowania wypełnił do końca" (VIII Międzynarodowy Turniej Stużb Mundurowych w Piłce Halowej im. podkom. Andrzeja Struja, 2017). Jednocześnie podkreśla się: „Dla środowiska policyjnego to bardzo istotne wydarzenie, kształtujące kulturę organizacyjną formacji. Turniej popularyzuje sport, a w szczególności piłkę nożną, która cieszy się niewątpliwie największym zainteresowaniem w środowisku policyjnym oraz wśród innych służb mundurowych. Poza aspektem sportowym spotkanie ma także na celu zacieśnienie kontaktów międzynarodowych pomiędzy reprezentacjami oraz integrację formacji mundurowych" (VIII Międzynarodowy Turniej..., 2017). Innym przykładem przedsięwzięcia integrującego policjantów jest Charytatywny Bal Oficerski Policji, którego tradycja sięga 1929 roku (Czwarty Charytatywny Bal Oficerski Policji, 2017). Środki zbierane w trakcie uroczystości są przekazywane Fundacji Pomocy Wdowom i Sierotom po Poległych Policjantach. Dodatkowo należy nadmienić, że na balu prezentowała się i grała Orkiestra Reprezentacyjna Policji, co również można zaliczyć do kategorii działań budujących kulturę policyjną.

Ceremoniał policyjny, rozumiany jako „zbiór podstawowych metod i form organizacyjnych przebiegu uroczystości państwowych, policyjnych, patriotycznych i patriotyczno-religijnych obchodzonych i realizowanych w policji" (Ceremoniał policyjny, 2015), stanowi istotny aspekt kultury policyjnej, ponieważ: „ma na celu kultywowanie policyjnych tradycji, integrowanie środowiska oraz 
umacnianie pozytywnego wizerunku Policji w społeczeństwie" (Działoszyński, 2012).Wśród najważniejszych uroczystości policyjnych można wymienić Święto Policji, ślubowanie, uroczystości pogrzebowe, wręczanie orderów i odznaczeń, pożegnanie policjantów, ślub czy wpis do Księgi Pamięci. Obchody te są niekiedy relacjonowane w środkach masowego przekazu.

Współpraca środowiska policyjnego może przebiegać na zróżnicowanych polach: od stowarzyszeń działających przy policji, poprzez kręgi naukowe, medialne, organizacje międzynarodowe, do relacji z emerytami i rencistami, kapelanami, związkami zawodowymi czy klasami policyjnymi ${ }^{3}$. Mottem International Police Association (International Police Association, 2017) jest hasło w języku esperanto „Servo per Amikeco” („służyć poprzez przyjaźń), natomiast główny cel to budowanie więzi bez względu na narodowość oraz promowanie współpracy na różnych szczeblach.

W tym zestawieniu warto nadmienić inne formy rozwoju i współdziałania na rzecz rozwoju kultury policyjnej: doskonalenie wizerunku całej formacji, zasady etyki zawodowej i regulamin musztry, wprowadzenie jednolitych symboli wizerunkowych, badania nad historią i tradycją policji.

\section{PODSUMOWANIE}

W ramach podsumowania warto przytoczyć słowa byłego Komendanta Głównego Policji, gen. insp. Marka Działoszyńskiego, które wypowiedział na forum Ogólnopolskiej Konferencji „Kultura organizacyjna w służbach mundurowych”: „Polska Policja prowadzi szereg działań w zakresie budowania kultury organizacyjnej. Nie jest to jednak łatwe, by realizować to zadanie w tak dużej formacji, jaką jest Policja. Każda instytucja składa się z wielu elementów organizacyjnych, takich jak system zarządzania, i innych czynników wpływających na sprawność działania. W naszej formacji to także ceremoniał i wartości. Stanowią one fundament podejścia policjantów do munduru i służby. Suma tych elementów to

3 Przykładowo, klasa policyjna w II Liceum Ogólnokształcącym w Toruniu oferuje „zajęcia edukacji policyjnej z zakresu kryminalistyki, prewencji i podstaw prawa, zajęcia edukacyjne z podstaw psychologii, warsztaty z zakresu samoobrony i pierwszej pomocy przedmedycznej, przygotowanie do procesu rekrutacyjnego do szkół policyjnych, wyjazdy szkoleniowo-kondycyjne, rozszerzony program nauczania zajęć edukacyjnych historii, języka obcego oraz jednych zajęć edukacyjnych wskazanych przez ucznia”. Oferta edukacyjna NA ROK SZKOLNY 2017/2018. (2017). Pobrane z: http://www.drugielo.torun.pl/?q=node/16. 
skarbnica wiedzy, jak budować kulturę organizacyjną w komunikacji zewnętrznej i wewnętrznej" (Ogólnopolska konferencja nt. kultury organizacyjnej w służbach mundurowych, 2017). Kultura policyjna to suma wszystkich działań policyjnych, wyróżniających ją na tle innych formacji mundurowych, a jednocześnie to zestaw specyficznych reguł, zachowań, języka. Obecnie prowadzonych jest coraz więcej badań, które mają wyjaśniać i prezentować poszczególne części składowe tej kultury organizacyjnej, co pozwoli na lepsze rozumienie policji nie tylko przez jej funkcjonariuszy, ale także obywateli. Warto bowiem pokazywać, że służba nie polega wyłącznie na wręczaniu mandatów, ale na edukowaniu, że policjanci nie zawsze są formalistami, ale ludźmi z pasją.

\section{BiBLIOGRAFIA:}

VIII Międzynarodowy Turniej Stużb Mundurowych w Piłce Halowej im. podkom. Andrzeja Struja. (2017). Pobrane z: http://www.policja.pl/pol/aktualnosci/138707,VIII-Miedzynarodowy-Turniej-Sluzb-Mundurowych-w-pilce-halowej-impodkom-Andrzeja.html.

Beal, Ch. (2017). Thank God for police culture. Pobrane z: http://www.policejournalsa. org.au/0112/39a.html.

Bogdalski, P., Świderski, M., Wojtaszczyk, K.A. (red.). (2015). Słownik wiedzy o policji. Warszawa: Oficyna Wydawnicza ASPRA-JR.

Cieślarczyk, M. (2003). O potrzebie i możliwościach badania problemów kultury organizacyjnej w siłach zbrojnych. W: M. Cieślarczyk, E. Pomykała (red.), Kultura organizacyjna w siłach zbrojnych. Warszawa: Akademia Obrony Narodowej.

Cieślarczyk, M. (2006). Kultura bezpieczeństwa i obronności. Siedlce: Wydawnictwo Akademii Podlaskiej.

Cieślarczyk, M. (2009). Teoretyczne i metodologiczne podstawy badania problemów bezpieczeństwa i obronności państwa. Siedlce: Wydawnictwo Akademii Podlaskiej.

Cockcroft, T. (2013). Police Culture. Themes and Concepts. Londyn-Nowy Jork: Routledge.

Czwarty Charytatywny Bal Oficerski Policji. (2017). Pobrane z: http://www.policja.pl/ pol/aktualnosci/138263,Czwarty-Charytatywny-Bal-Oficerski-Policji.html.

Działoszyński, M. (2012). W: G. Jach (red.), Ceremoniał policyjny. Warszawa, Legionowo: Wydział Wydawnictw i Poligrafii. Centrum Szkolenia Policji.

Hołyst, B. (2011). Policja na świecie. Warszawa: LexisNexis Polska.

Hołyst, B. (2013). Policja na świecie. Warszawa: LexisNexis Polska.

International Police Association. (2017). Pobrane z: http://www.ipa-iac.org/.

Konieczna, K. (2015). Kwestie przywództwa w Policji w świetle kultury organizacyjnej. W: M. Hermanowski, K. Oblińska (red.), Kultura organizacyjna w stużbach mundurowych. Poznań-Warszawa: Wyższa Szkoła Umiejętności Społecznych; Komenda Główna Policji. 
O’Neill, M., Singh, A.-M. (2007). Police Occupational Culture: New Debates and Directions. Pobrane z: https://usir.salford.ac.uk/16770/1/Intro_to_Police_Culture_pre-print.pdf.

Oferta edukacyjna na rok szkolny 2017/2018. (2017). http://www.drugielo.torun.pl/?q $=$ node $/ 16$.

Ogólnopolska konferencja nt. kultury organizacyjnej w służbach mundurowych. (2017). http://webcache.googleusercontent.com/search?q=cache:M7GO9qK4hcsJ:www. policja.pl/pol/aktualnosci/106021,Ogolnopolska-konferencja-nt-kultury-organiz acyjnej-w-sluzbach-mundurowych.pdf $+\& c d=1 \& h l=p l \& c t=c l n k \& g l=p l$.

Paliszkiewicz, J. (2010). Kultura oparta na zaufaniu. W: E. Skrzypek (red.), Etyka a jakość i efektywność organizacji. Lublin: Katedra Zarządzania Jakością i Wiedzą. Wydział Ekonomiczny. Uniwersytet Marii Curie-Skłodowskiej.

Pływaczewski, W., Kędzierska, G. (red.). (2001). Leksykon policyjny. Szczytno: Wydawnictwo Wyższej Szkoły Policji.

Policja najlepiej oceniana stużba mundurową. (2017). Pobrane z: http://www.policja. $\mathrm{pl} /$ pol/aktualnosci/123998,Policja-najlepiej-oceniana-formacja-mundurowa.html. Większość Polaków deklaruje swoje zaufanie do policji. (2017). Pobrane z: http://www. policja.pl/pol/aktualnosci/122393, Wiekszosc-Polakow-deklaruje-swoje-zaufaniedo-Policji.html. 